\title{
Pollution induced in marine environment
}

\section{Introduction}

Marine pollution is the introduction of hazardous / harmful contaminants into the marine environment. Such as oil, raw sewage and pesticides (insect killer) are just a few examples of the contaminants found in oceans and other marine environments. Oil drops (spills) chemical pollution and sewage pollution have a number of adverse effects on organisms that lives in marine environment. Pesticides and other chemicals build up in the fatty tissues of marine animals affecting their reproduction capabilities. Raw sewage supports the algae growth which can have a disturbing impact on the plants and animals in a marine environment.

\section{Factors that create pollutions in marine environment and their impacts on marine life}

There are different types of marine environmental pollutants which are dangerous for marine life. Some of them are more obvious than others but all are takes part to an unhealthy the marine environment and many times they causes death of its creatures. Some of these factors are bellow

\section{Effects of oil}

A "National Research Council" report narrows oil in the ocean to four types:

\section{Natural seeps \\ 2. Petroleum extraction \\ 3. Petroleum transportation \\ 4. Petroleum consumption}

Oil is dangerous to marine life in several ways. According to the "National Oceanic and Atmospheric Administration" (NOAA) if furbearing mammals or birds get oil on their fur or feathers they may not fly or move properly, maintain body temperature or feed. The oil washes up on beaches and contaminates nesting areas and feeding grounds. As marine mammals try to clean themselves they may ingest oil which can poison them. Although fish and shellfish aren't impacted directly long-term exposure may lead to reduced respiration, organ damage, reduced growth and may negatively impact reproduction and larva development and survival. Oil also block up the gills of the fish that live there and suffocates them. When oil floats on the surface, it blocks sunlight and prevents marine plants from using light for photosynthesis. These plants are important parts of the food chain and the reef habitats found in the oceans (Figure 1).

\section{Toxic materials}

Toxic materials have side-effect from modern living. Some of toxic pollution sources include:

1. Industry and sewage waste discharge

2. Pesticides

3. Nuclear power plants

\author{
Volume 4 Issue 3 - 2017
}

\section{Rafique Mengal}

Department of Microbiology, Balochistan University of information technology and Management Sciences Quetta, Pakistan

Correspondence: Rafique Mengal, Department of Microbiology, Balochistan University of information technology and Management Sciences Quetta, Pakistan,

Email rafiquealam9I@hotmail.com

Received: November 06, 2017 | Published: March 09, 2017

\section{Nuclear waste dumps}

5. Nuclear submarines

6. Household cleaning products

Pollutants find their way into the ocean and sink to the bottom. Bottom feeding organisms ingest these chemicals and contaminate the food chain. The smaller fish is eaten by the larger fish which is then eaten by a human. Toxins build up in the tissues of the people who eat the contaminated fish and may lead to illnesses like cancer, reproductive disorders, birth defects and other long-term health problems.

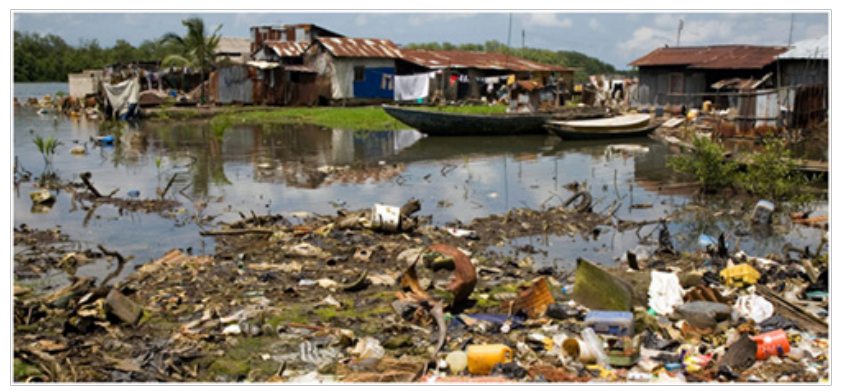

Figure I The common man-made pollutants that reach the ocean include pesticides, herbicides, chemical fertilizers, detergents, oil, sewage, plastics and other solids. Many of these pollutants collect at the ocean's depths where they are consumed by small marine organisms and introduced into the global food chain.

\section{Trash and other wastes}

Medical waste, balloons, plastic bags, milk packets and soda cans all find their way into the oceans of the world. These items float in the water and wash up on beaches. According to the "Environmental Protection Agency" marine waste creates health risks for marine life. Birds, turtles and fish ingest a variety of plastic items and their digestive systems become closed. Sea turtles are attracted to floating plastic bags which appear to be jellyfish, one of their favorite treats. The plastic bags block their digestive system and cause a slow and painful death. Various pieces of trash cause entanglement, starvation, 
drowning and strangulation. When the wastes wash up onto beaches and into marshes it ruins breeding grounds and habitats. Marine plants may be strangled by debris and die.

\section{Facts and figures on the effects of marine pollution}

According to a report published in the "Review of Research Journal" the Marine Academy's Oceanography website reports that "there are over 46,000 pieces of plastic floating in each square mile of ocean off of the Northeast coast of the United States." The plastic contributes to the death of millions of sea birds and 100,000 marine mammals each year.

A "Center for Biological Diversity report" states that 82,000 birds of 102 species were likely harmed or killed and In addition approximately 6,165 sea turtles, 25,900 marine mammals and an unknown number of fish were harmed or killed within a year due to the British Petroleum oil spill in the Gulf of Mexico. And in the midJune, 2010 the spill contributed to the death of 658 sea birds, 279 sea turtles, 36 sea mammals, and countless fish ("Annette McDermott" Natural Healing Specialist"). ${ }^{1-3}$

\section{Acknowledgements}

None.

\section{Conflict of interest}

The author declares no conflict of interest.

\section{References}

1. www.nepa.gov.jm/Impacts $\% 20$ of $\% 20$ Pollution $\% 20$ on $\% 20$ the $\% 20$

2. Derraik JGB. The pollution of the marine environment by plastic debris: a review. Marine Pollution Bulletin. 2002;44:842-852.

3. greenliving.lovetoknow.com/Effects_of_Ocean_Pollution_on_Marine_L 